\title{
Correction to: Three-dimensional complete gradient Yamabe solitons with divergence-free Cotton tensor
}

\section{Shun Maeta ${ }^{1}$}

Published online: 7 July 2020

(c) Springer Nature B.V. 2020

\section{Correction to: Annals of Global Analysis and Geometry https://doi.org/10.1007/s10455-020-09722-9}

In the original article the formula chapter 4, just above Remark 4.2 in the paragraph starting with Case (2) the formula should read:

$$
F^{\prime \prime}=-\rho>0
$$

Publisher's Note Springer Nature remains neutral with regard to jurisdictional claims in published maps and institutional affiliations.

The original article can be found online at https://doi.org/10.1007/s10455-020-09722-9.

Shun Maeta

shun.maeta@gmail.com; maeta@riko.shimane-u.ac.jp

1 Department of Mathematics, Shimane University, Nishikawatsu 1060, Matsue 690-8504, Japan 